\title{
Complications following lengthening of spinal growing implants: is postoperative admission necessary?
}

\author{
K. Aaron Shaw, DO, ${ }^{1}$ Nicholas D. Fletcher, MD, ${ }^{2}$ Dennis P. Devito, MD, ${ }^{3}$ and Joshua S. Murphy, MD ${ }^{3}$ \\ 'Department of Orthopaedic Surgery, Dwight D. Eisenhower Army Medical Center, Fort Gordon; ${ }^{2}$ Department of Orthopaedics, \\ Emory University, Atlanta; and ' ${ }^{2}$ epartment of Pediatric Orthopaedic Surgery, Children's Healthcare of Atlanta, Georgia
}

\begin{abstract}
OBJECTIVE The aim of this study was to evaluate the effect of postoperative admission status on 30-day perioperative complications in patients with growing spinal instrumentation undergoing surgical lengthening.

METHODS This retrospective case-control study of records from the 2014-2015 National Surgical Quality Improvement Program-Pediatric database was performed to identify surgical lengthening procedures of spinal implants in patients with growing instrumentation by Current Procedural Terminology code. The 30-day postoperative complications were classified according to the Clavien-Dindo system. Patients were subdivided according to their postsurgical admission status. Admission status, American Society of Anesthesiologists (ASA) Physical Status classification, tracheostomy, neuromuscular diagnosis, ventilator dependence, and nutritional support were considered as possible risk factors in univariate and multivariate logistic regression analyses.
\end{abstract}

RESULTS A total of 796 patients were identified (mean age $9.09 \pm 3.44$ years; $54 \%$ of patients were female), of whom $73 \%$ underwent lengthening on an inpatient basis. Patients with a tracheostomy or ventilator dependence were more likely to be admitted postoperatively. The overall rate of major complications was 3.5\% and did not differ based on admission status $(2.8 \%$ inpatient vs $3.8 \%$ outpatient, $p=0.517)$. On univariate analysis, ventilator dependence $(9.5 \%$ vs $2.7 \%, p=0.002)$, need for nutritional support $(7.1 \%$ vs $2.5 \%, p=0.006)$, and ASA class $>$ II $(4.8 \%$ vs $1.3 \%, p=0.04)$ placed patients at a higher risk for any postoperative complications. Multivariate analysis identified only ventilator dependence as an independent risk factor for any perioperative complication.

CONCLUSIONS Postoperative admission status did not affect the rate of 30-day perioperative complications, readmission, or rate of unplanned operations following lengthening of growing spinal instrumentation. Outpatient lengthening appears to be safe; however, consideration for postoperative admission should be given for those who are ventilator dependent.

https://thejns.org/doi/abs/10.3171/2018.2.PEDS1827

KEYWORDS early-onset scoliosis; growing instrumentation; spinal lengthening; admission status; postoperative complications; NSQIP-P; spine

$\mathrm{E}$ ARLY-ONSET scoliosis is commonly treated with growth-friendly procedures that allow for continued spinal growth in order to prevent iatrogenic thoracic insufficiency. ${ }^{4,15,16}$ Many forms of instrumentation used to treat early-onset scoliosis require periodic lengthening procedures to facilitate continued growth. Although this has been shown to accommodate continued growth, ${ }^{30}$ there is an increasing risk of complication, at a rate of $24 \%$ for each additional surgical lengthening. ${ }^{2}$

Complications associated with growing spinal instrumentation have been reported to be as high as $84 \%$ dur- ing the course of treatment. ${ }^{2,24,29}$ Part of the reason for this high complication rate is patient characteristics, with early-onset scoliosis having a high association with neuromuscular or syndromic conditions. ${ }^{24}$ As such, postoperative admission following surgical lengthening has been common practice after exposure to a general anesthetic. With the recent introduction of magnetically controlled growing rods, the ability to perform outpatient implant lengthening has become common practice with the touted advantage over traditional growing implants both on risk of complications and patient quality of life. ${ }^{14}$ However, no

ABBREVIATIONS ASA = American Society of Anesthesiologists; NSQIP-P = National Surgical Quality Improvement Program-Pediatric; PUF = Participant User File. SUBMITTED January 11, 2018. ACCEPTED February 13, 2018.

INCLUDE WHEN CITING Published online April 27, 2018; DOI: 10.3171/2018.2.PEDS1827. 
study to date has assessed the safety of outpatient lengthening of growing spinal implants.

We hypothesized that the 30-day perioperative complication rate after lengthening of spinal instrumentation would be similar between outpatient and inpatient lengthening procedures.

\section{Methods}

A retrospective cohort study was conducted using data from the American College of Surgeons National Surgical Quality Improvement Program-Pediatric (NSQIP-P) database. NSQIP-P is a multiinstitutional pediatric (age < 18 years) surgical outcomes database containing preoperative, surgical, and 30-day outcome variables collected based on a systematic sampling process to ensure proportional diversity in selection using an 8-day sampling cycle from more than 60 pediatric institutions. ${ }^{19}$ NSQIP-P data are continuously audited and validated and are compiled into Participant User Files (PUFs) for use in quality improvement and surgical outcomes research. The 20142015 NSQIP-P PUF was used for this study. The NSQIP-P PUF data contain no patient identifiers, and this research was determined to be exempt from IRB review by the local IRB and Human Subjects Protection Office.

The study cohort was identified by Current Procedural Terminology code 22849 for surgical lengthening of a growing spinal prosthesis. The primary independent variable of interest was the hospital-defined postoperative admission status, defined as either inpatient admission after surgery or outpatient surgery with discharge following surgery. Other variables evaluated included age, sex, presence of a tracheostomy, seizure disorder, neuromuscular condition, nutritional support (including total parenteral nutrition or assisted feeding via gastrostomy or nasogastric or jejunal devices), ventilator dependence at the time of surgery (including continuous or bilevel positive airway pressure), and American Society of Anesthesiologists (ASA) Physical Status classification as defined by the treating anesthesiologist.

The primary outcome was the rate of any surgical complication within 30 days. Postoperative complications were stratified according to the Clavien-Dindo classification system as modified by Sink et al. for orthopedic procedures. ${ }^{33}$ Complications are subdivided as grade I (not included in the NSQIP-P database), II (superficial wound infection, urinary tract infection, seizure, transfusion, venous thromboembolism, pneumonia), III (wound dehiscence, neurological deficit, systemic sepsis, reoperation, readmission, pulmonary embolism), IV (reintubation, coma, septic shock, implant failure, cerebrovascular accident), or V (death) ${ }^{33}$ Complications were categorized as minor if they were Clavien-Dindo grade I or II, and major for grades III and higher.

Statistical analysis was performed using IBM SPSS (version 24, IBM Corp.). Significance was set at $\mathrm{p}<0.05$. Univariate analyses using the chi-square test were performed to assess for relationships between categorical predictor variables and the occurrence of postoperative complications. Univariate factors identified as having statistically significant associations with the occurrence of any complication were entered into a stepwise multivariable binary logistic regression model to determine independent contributions to the occurrence of complications.

\section{Results}

A total of 796 patients were identified (mean age $9.09 \pm$ 3.44 years; $54 \%$ of patients were female) as having undergone a spinal lengthening procedure for growth-friendly instrumentation. Recording of preoperative diagnoses varied, with $34.4 \%(\mathrm{n}=274)$ reported as unclassified scoliosis, $14.7 \%(\mathrm{n}=117)$ as previous spinal hardware implantation, $12.6 \%(\mathrm{n}=100)$ as congenital spine deformity, and $13.1 \%(\mathrm{n}=104)$ as having no listed diagnosis code. Three hundred twelve patients had a documented neuromuscular condition at the time of surgery (39.2\%); $27.9 \%$ $(\mathrm{n}=87 / 312)$ had cerebral palsy and the remaining patients had conditions that consisted of various forms of muscular dystrophy, myelodysplasia, and spinal muscular atrophy. A seizure disorder was present in 96 patients (12.06\%), 94 were ventilator dependent (11.8\%), and 72 had a tracheostomy $(9.04 \%)$. The majority of cases were graded as ASA class III $(\mathrm{n}=460,57.8 \%)$ followed by ASA class II $(\mathrm{n}=$ $277,34.8 \%)$ and ASA class I $(n=25,3.1 \%)$.

Of the identified 796 cases, $73 \%$ were performed on an inpatient basis. There was no significant difference in mean patient age (inpatient: $9.05 \pm 3.66$ years vs outpatient: $9.22 \pm 2.75$ years; $p=0.52$ ), sex (outpatient: $56.3 \%$ female patients vs inpatient: $53.7 \%$ female patients; $\mathrm{p}=$ 0.506 ), neuromuscular diagnosis (inpatient: $39.6 \%$ vs outpatient: $40.9 \% ; \mathrm{p}=0.56$ ), or seizure disorder (inpatient: $11.8 \%$ vs outpatient: $12.7 \% ; \mathrm{p}=0.747$ ) and postoperative admission status. However, patients with a tracheostomy (10.4\% vs $5.1 \%$; $p=0.021)$ and ventilator-dependent patients $(13.2 \%$ vs $7.9 \%$; $p=0.043)$ were more likely to be admitted to the hospital postoperatively after a lengthening procedure.

Seventy-five postoperative complications (not including the number of blood transfusions) were reported in 46 patients $(5.8 \%)$ in the first 30 days following surgery (Table 1). When subdivided according to the Clavien-Dindo classification system, there were 8 patients with a grade II complication and 38 patients with a total of 67 grade III complications. Four patients experienced both grade II and III complications. The overall rate of major complication requiring readmission or reoperation was $3.5 \%$.

The most common complication within 30 days of surgery was readmission $(n=28$; Table 2$)$. The most common listed diagnosis for readmission was wound infection $(\mathrm{n}=$ $5)$, followed by implant-related complication $(n=4)$, sepsis $(n=3)$, wound dehiscence $(n=2)$, and pneumonia $(n=2)$. Reoperation occurred in 18 patients, with reinsertion of implants being most common $(n=5)$, followed by irrigation and debridement $(n=4)$. Wound exploration and incisional dehiscence repair occurred in 1 patient each, with 4 other patients undergoing procedures other than spine surgery (bronchoscopy, fecal disimpaction, cystourethroscopy, and CSF shunt procedure) and 3 patients having no listed procedural codes.

Overall, the rate of a major complication did not differ based on admission status (2.8\% inpatient vs $3.8 \%$ out- 
TABLE 1. Summary of all complications experienced within the 30-day perioperative period after surgical lengthening of spinal growing instrumentation

\begin{tabular}{lc}
\hline \multicolumn{1}{c}{ Complication } & No. of Occurrences (\%) \\
\hline Unplanned readmission & $28(3.5)$ \\
\hline Blood transfusion & $27(3.4)$ \\
\hline Unplanned reop & $18(2.2)$ \\
\hline Superficial dehiscence & $14(1.8)$ \\
\hline Superficial infection & $4(0.5)$ \\
\hline Deep infection & $3(0.4)$ \\
\hline Sepsis & $3(0.4)$ \\
\hline Pneumonia & $2(0.3)$ \\
\hline Urinary tract infection & $1(0.1)$ \\
\hline Venous thromboembolism & $1(0.1)$ \\
\hline Nerve injury & $1(0.1)$ \\
\hline Implant failure & $0(0)$ \\
\hline Unplanned reintubation & $0(0)$ \\
\hline Deep dehiscence & $0(0)$ \\
\hline
\end{tabular}

patient, $\mathrm{p}=0.517$ ). There was a $3.5 \%$ rate of readmission and a $2.2 \%$ rate of unplanned reoperation. On univariate analysis, ventilatory dependence ( $9.5 \%$ vs $2.7 \%$ ), need for nutritional support (7.1\% vs $2.5 \%$ ), and ASA classification $>$ II $($ ASA class $>$ II $[n=494] 4.8 \%$ vs ASA class $\leq$ II $[n$ $=302] 1.3 \%$ ) placed patients at a higher risk for any postoperative complications (Table 3). Multivariate analysis identified ventilator dependence as an independent risk factor for any postoperative complications within 30 days following surgery.

\section{Discussion}

Early-onset scoliosis is a challenging clinical entity with an evolving approach to its surgical treatment. While the recent introduction of magnetically expandable growing rods has changed the surgical approach to many patients, the use of instrumentation requiring regular surgical lengthening is still favored in certain clinical scenarios, and many patients still have such implants in place that continue to require surgical lengthening. In this review of pediatric patients undergoing a spinal lengthening procedure for growth-friendly instrumentation, we found an overall rate of perioperative complications within 30 days of surgery of $6.3 \%$. Of the children undergoing a lengthening procedure, $73 \%$ were admitted to the hospital; however, the postoperative complication rate did not differ between these patients and those undergoing outpatient lengthening. Only ventilator dependence was found to be an independent predictor for perioperative complication.

Growing rod instrumentation, including rib-based distraction prostheses and traditional growing rods, has been a popular treatment for early-onset scoliosis for many years. This method has evolved as a means to address the occurrence of restrictive pulmonary disease and thoracic insufficiency that developed in patients who underwent early, definitive spinal fusions., ${ }^{4,15}$ However, given the required repetitive surgical lengthening procedures, the
TABLE 2. Summary of reasons for postoperative readmission within 30 days of undergoing a lengthening of a growth-friendly spinal implant

\begin{tabular}{lc}
\hline \multicolumn{1}{c}{ Readmission Diagnosis } & No. of Occurrences \\
\hline Surgical site infection & 5 \\
\hline Implant complication & 4 \\
\hline Sepsis & 3 \\
\hline Wound dehiscence & 2 \\
\hline Fever & 2 \\
\hline Pneumonia & 2 \\
\hline Constipation & 2 \\
\hline Nerve injury & 1 \\
\hline Urinary tract infection & 1 \\
\hline Respiratory distress & 1 \\
\hline Tracheostomy complication & 1 \\
\hline CSF shunt complication & 1 \\
\hline Chest pain & 1 \\
\hline Viral infection & 1 \\
\hline Tachycardia & 1 \\
\hline
\end{tabular}

risk of surgical complications is present. Bess et al. ${ }^{2}$ reported the complication rate for patients undergoing traditional growing rod instrumentation, finding that $58 \%$ of patients develop at least one complication over the treatment course, with younger patient age and each additional lengthening procedure independently increasing the risk of developing a complication. The current study found a much lower complication rate, $6.3 \%$, for a single lengthening procedure. The average patient treated with growthfriendly spinal instrumentation undergoes an average of 4-6 surgical lengthening procedures. ${ }^{2,37}$ Extrapolating the reported $6.3 \%$ complication rate per lengthening would increase the perioperative complication rate to $25.2 \%$ $37.8 \%$ over the entire treatment course.

Unplanned readmission was the most common complication, experienced by $3.5 \%$ of the pediatric cohort. Wound infection and implant complications were the most common etiologies for readmission $(n=14)$, accounting for $50 \%$ of all readmissions. Of the patients readmitted for a wound infection, $78 \%$ required an unplanned return to the operating room. Long-term studies, however, have indicated that implant-related complications are the most common, accounting for as much as $77 \%$ of all complications..$^{20}$ Given the short follow-up in the NSQIP-P data set, only 30 days from surgery, these complications are less likely to occur in the current patient cohort and may artificially deflate the overall complication rate. Numerous surgical factors have been identified to account for the incidence of implant-related postoperative complications; ${ }^{1,38}$ however, given the limitation of the data set, we are unable to comment on the technical aspects of these procedures and how they might have affected the postoperative complication rates.

The presence of a tracheostomy and presurgical ventilator dependence (including the use of continuous and bilevel positive airway pressure) were identified as risk 
TABLE 3. Results of univariate and multivariate analyses, identifying risk factors for any postoperative complication in children undergoing lengthening of growing spinal prostheses

\begin{tabular}{lcccc}
\hline \multicolumn{1}{c}{ Variable } & \% Complication & \% No Complication & p Value & Multivariate OR (95\% Cl) \\
\hline Inpatient & 2.8 & 97.2 & 0.517 & \multirow{2}{*}{$1.23(0.48-3.15)$} \\
\hline Outpatient & 3.8 & 96.2 & & \\
\hline Sex & 42.8 male & 45.7 male & 0.766 & \\
\hline Tracheostomy & 4.2 & 95.8 & 0.754 & \\
\hline Seizure disorder & 17.8 & 11.8 & 0.338 & \\
\hline Ventilator & 9.5 & 90.5 & 0.001 & $4.2(1.44-12.29)$ \\
\hline Nutritional support & 7.1 & 92.9 & 0.006 & $2.01(0.79-5.17)$ \\
\hline ASA class $>$ II & 4.8 & 95.2 & 0.009 & $2.79(0.88-8.85)$ \\
\hline Neuromuscular & 4.7 & 95.3 & 0.233 & \\
\hline
\end{tabular}

factors for postoperative readmission. Additionally, univariate analysis identified ventilator dependence, need for preoperative nutritional support, and higher ASA classification as risk factors for any postoperative complication within 30 days of surgery. Risk factors for postoperative complications and infections have been reported previously. ${ }^{8,21,28}$ Higher ASA classification is a common risk factor identified in the literature, with classes greater than II being associated with postoperative complications, ${ }^{8,21}$ as reported in the current study.

Several studies have examined the outcomes of pediatric patients with significant respiratory compromise who underwent spinal surgery. Wazeka et al ${ }^{39}$ reported the outcomes of 21 pediatric patients with severe restrictive lung disease, $19 \%$ of whom were ventilator dependent, undergoing spinal arthrodesis $(85 \%$ of which were circumferential anterior and posterior fusions), with $19 \%$ of patients developing a postoperative major pulmonary complication (2 pleural effusions and 2 cases of pneumonia). Payo et al. ${ }^{23}$ reviewed 24 patients younger than 19 years with presurgical ventilator support. Although none of this cohort (70\% of whom had a neuromuscular scoliosis) required a tracheostomy, there was a $58 \%$ complication rate at a mean follow-up of 32 months, with $50 \%$ of these complications being labeled as a major complication according to the Clavien-Dindo system. ${ }^{23}$ Gill et al. ${ }^{11}$ found that patients with neuromuscular conditions and preexisting respiratory failure, however, can safely undergo surgery without significant change in their respiratory function and without major cardiac or pulmonary complications.

No previous studies have assessed the safety of outpatient lengthening of growth-friendly spinal implants in patients with a tracheostomy and/or ventilator dependence. However, obstructive sleep apnea and ventilatory dependence have shown a high association with postoperative complications and respiratory compromise for pediatric patients undergoing adenotonsillectomy. ${ }^{5,740}$ As such, the American Academy of Pediatrics has proposed guidance for the perioperative anesthesia environment of pediatric patients undergoing surgery, recommending postoperative admission or prolonged monitoring for any patient with a history of obstructive sleep apnea. ${ }^{25}$

The necessity of nutritional support was also recog- nized as a risk factor for postoperative complication. Malnutrition has been reported to be a common risk factor for postoperative complication in adults; ${ }^{3,27}$ however, it has not been well investigated in cases of pediatric scoliosis. Postoperative gastrointestinal complications are not uncommon in pediatric patients, especially in patients with neuromuscular disorders. ${ }^{34}$ The presence of nutritional support, by way of total parenteral nutrition or nasogastric, gastrostomy, or jejunal feeding, was associated with an increased rate of postoperative complications. However, previous studies have shown that gastrostomy tube feeding can have a significantly positive effect on weight gain and nutritional indices in pediatric neuromuscular disorders. ${ }^{31,35,36}$ Jalanko et al. ${ }^{13}$ found that gastric myoelectric power increases in patients with spastic neuromuscular disorders who undergo surgical correction of scoliosis. This was found to be significantly correlated with the postoperative sagittal balance and associated with prolonged paralytic ileus. However, there was minimal effect on the nutritional state.

Ultimately, no association was found between postoperative admission status and the rate of perioperative complications. This reflects the data of similar studies in the adult spine literature, demonstrating that the rate of perioperative complications for outpatient cervical ${ }^{17,22,26}$ and lumbar ${ }^{9,32}$ surgery is no different from that of inpatient procedures. As outpatient orthopedic and spine surgeries have been shown to be effective and produce high patient satisfaction in review of national health care databases, ${ }^{10,12,18}$ performing outpatient surgical lengthening of growth-friendly spinal implants could help improve patient satisfaction. Additionally, hospital expenses account for up to $83 \%$ of the direct costs for traditional growing rod lengthening procedures. ${ }^{6}$ Performing outpatient lengthening for indicated patients could significantly reduce surgical costs while improving hospital resource utilization.

There are several limitations in the interpretation of this study. The occurrence of a postoperative complication is restricted to within 30 days of surgery. Although this study was focused on the implication of postoperative admission status on short-term complications, we are unable to obtain a true understanding of the long-term complication profile or to assess the cumulative complication 
profile over the complete course of spinal lengthening. Additionally, the reason why surgeons elected to admit certain patients and not others is a point that is unable to be confirmed given the restraints of the data, limiting the extrapolation of the results. The data also do not differentiate at which point each patient is in the course of his or her surgical treatment, or the number of prior lengthening procedures. Previous studies have shown that an increasing number of lengthening procedures increases the risk of complications, ${ }^{37}$ a finding on which we are unable to comment. Given that NSQIP-P is a nationwide database, myriad surgeons were included, with an expected wide variation in surgical technique that cannot be accounted for in this analysis. Given the coding status, we were unable to subdefine the complication rate by the type of proximal anchorage, rib based versus spine, or the number of proximal anchorage points. In addition, surgical blood loss and transfusion protocols were not standardized across participating institutions.

\section{Conclusions}

Using a prospectively collected nationwide pediatric database, we defined the overall perioperative complication profile in patients undergoing a spinal lengthening procedure for early-onset scoliosis. Although, $73 \%$ of children in this cohort were admitted to the hospital, no significant difference in perioperative complications was found between those who underwent outpatient versus inpatient procedures. Outpatient lengthening appears to be safe for most patients; however, consideration for postoperative admission should be given to those who are ventilator dependent.

\section{References}

1. Akbarnia BA, Yaszay B, Yazici M, Kabirian N, Blakemore LC, Strauss KR, et al: Biomechanical evaluation of 4 different foundation constructs commonly used in growing spine surgery: are rib anchors comparable to spine anchors? Spine Deform 2:437-443, 2014

2. Bess S, Akbarnia BA, Thompson GH, Sponseller PD, Shah SA, El Sebaie H, et al: Complications of growing-rod treatment for early-onset scoliosis: analysis of one hundred and forty patients. J Bone Joint Surg Am 92:2533-2543, 2010

3. Bohl DD, Shen MR, Mayo BC, Massel DH, Long WW, Modi $\mathrm{KD}$, et al: Malnutrition predicts infectious and wound complications following posterior lumbar spinal fusion. Spine (Phila Pa 1976) 41:1693-1699, 2016

4. Bowen RE, Scaduto AA, Banuelos S: Does early thoracic fusion exacerbate preexisting restrictive lung disease in congenital scoliosis patients? J Pediatr Orthop 28:506-511, 2008

5. Brown KA: Outcome, risk, and error and the child with obstructive sleep apnea. Paediatr Anaesth 21:771-780, 2011

6. Charroin C, Abelin-Genevois K, Cunin V, Berthiller J, Constant H, Kohler R, et al: Direct costs associated with the management of progressive early onset scoliosis: estimations based on gold standard technique or with magnetically controlled growing rods. Orthop Traumatol Surg Res 100:469-474, 2014

7. Coté CJ, Zaslavsky A, Downes JJ, Kurth CD, Welborn LG, Warner LO, et al: Postoperative apnea in former preterm infants after inguinal herniorrhaphy. A combined analysis. Anesthesiology 82:809-822, 1995
8. Croft LD, Pottinger JM, Chiang HY, Ziebold CS, Weinstein SL, Herwaldt LA: Risk factors for surgical site infections after pediatric spine operations. Spine (Phila Pa 1976) 40:E112-E119, 2015

9. Debono B, Sabatier P, Garnault V, Hamel O, Bousquet P, Lescure JP, et al: outpatient lumbar microdiscectomy in France: from an economic imperative to a clinical standard-an observational study of 201 cases. World Neurosurg 106:891-897, 2017

10. Gaucher S, Bouam S, Maladry D, Bethoux JP, Philippe HJ: Outpatient cervical and lumbar spine surgery is feasible and safe: a consecutive single center series of 1449 patients. Neurosurgery 80:E185, 2017 (Letter)

11. Gill I, Eagle M, Mehta JS, Gibson MJ, Bushby K, Bullock R: Correction of neuromuscular scoliosis in patients with preexisting respiratory failure. Spine (Phila Pa 1976) 31:24782483, 2006

12. Hersht M, Massicotte EM, Bernstein M: Patient satisfaction with outpatient lumbar microsurgical discectomy: a qualitative study. Can J Surg 50:445-449, 2007

13. Jalanko T, Helenius I, Pakarinen M, Puisto V, Salminen P, Peltonen J, et al: Effects of surgical correction of neuromuscular scoliosis on gastric myoelectrical activity, emptying, and upper gastrointestinal symptoms. J Pediatr Gastroenterol Nutr 58:38-45, 2014

14. Jenks M, Craig J, Higgins J, Willits I, Barata T, Wood H, et al: The MAGEC system for spinal lengthening in children with scoliosis: a NICE medical technology guidance. Appl Health Econ Health Policy 12:587-599, 2014

15. Karol LA: Early definitive spinal fusion in young children: what we have learned. Clin Orthop Relat Res 469:13231329,2011

16. Karol LA, Johnston C, Mladenov K, Schochet P, Walters P, Browne RH: Pulmonary function following early thoracic fusion in non-neuromuscular scoliosis. J Bone Joint Surg Am 90:1272-1281, 2008

17. Khanna R, Kim RB, Lam SK, Cybulski GR, Smith ZA, Dahdaleh NS: Comparing short-term complications of inpatient versus outpatient single-level anterior cervical discectomy and fusion: an analysis of 6940 patients using the ACS-NSQIP database. Clin Spine Surg 31:43-47, 2018

18. Krywulak SA, Mohtadi NG, Russell ML, Sasyniuk TM: Patient satisfaction with inpatient versus outpatient reconstruction of the anterior cruciate ligament: a randomized clinical trial. Can J Surg 48:201-206, 2005

19. Kuo BJ, Vissoci JR, Egger JR, Smith ER, Grant GA, Haglund MM, et al: Perioperative outcomes for pediatric neurosurgical procedures: analysis of the National Surgical Quality Improvement Program-Pediatrics. J Neurosurg Pediatr 19:361-371, 2017

20. Liang J, Li S, Xu D, Zhuang Q, Ren Z, Chen X, et al: Risk factors for predicting complications associated with growing rod surgery for early-onset scoliosis. Clin Neurol Neurosurg 136:15-19, 2015

21. Linam WM, Margolis PA, Staat MA, Britto MT, Hornung R, Cassedy A, et al: Risk factors associated with surgical site infection after pediatric posterior spinal fusion procedure. Infect Control Hosp Epidemiol 30:109-116, 2009

22. McClelland S III, Passias PG, Errico TJ, Bess RS, Protopsaltis TS: Inpatient versus outpatient anterior cervical discectomy and fusion: a perioperative complication analysis of 259,414 patients from the Healthcare Cost and Utilization Project databases. Int J Spine Surg 11:11, 2017

23. Payo J, Perez-Grueso FS, Fernandez-Baillo N, Garcia A: Severe restrictive lung disease and vertebral surgery in a pediatric population. Eur Spine J 18:1905-1910, 2009

24. Phillips JH, Knapp DR Jr, Herrera-Soto J: Mortality and morbidity in early-onset scoliosis surgery. Spine (Phila Pa 1976) 38:324-327, 2013 
25. Polaner DM, Houck CS: Critical elements for the pediatric perioperative anesthesia environment. Pediatrics 136:12001205,2015

26. Purger DA, Pendharkar AV, Ho AL, Sussman ES, Yang L, Desai M, et al: Outpatient vs inpatient anterior cervical discectomy and fusion: a population-level analysis of outcomes and cost. Neurosurgery [epub ahead of print], 2017

27. Puvanesarajah V, Jain A, Kebaish K, Shaffrey CI, Sciubba DM, De la Garza-Ramos R, et al: Poor nutrition status and lumbar spine fusion surgery in the elderly: readmissions, complications, and mortality. Spine (Phila Pa 1976) 42:979983, 2017

28. Rumalla K, Yarbrough CK, Pugely AJ, Koester L, Dorward IG: Spinal fusion for pediatric neuromuscular scoliosis: national trends, complications, and in-hospital outcomes. J Neurosurg Spine 25:500-508, 2016

29. Sankar WN, Acevedo DC, Skaggs DL: Comparison of complications among growing spinal implants. Spine (Phila Pa 1976) 35:2091-2096, 2010

30. Sankar WN, Skaggs DL, Yazici M, Johnston CE II, Shah SA, Javidan P, et al: Lengthening of dual growing rods and the law of diminishing returns. Spine (Phila Pa 1976) 36:806809, 2011

31. Seguy D, Michaud L, Guimber D, Cuisset JM, Devos P, Turck D, et al: Efficacy and tolerance of gastrostomy feeding in pediatric forms of neuromuscular diseases. JPEN J Parenter Enteral Nutr 26:298-304, 2002

32. Singhal A, Bernstein M: Outpatient lumbar microdiscectomy: a prospective study in 122 patients. Can J Neurol Sci 29:249-252, 2002

33. Sink EL, Leunig M, Zaltz I, Gilbert JC, Clohisy J: Reliability of a complication classification system for orthopaedic surgery. Clin Orthop Relat Res 470:2220-2226, 2012

34. Skalsky AJ, Dalal PB: Common complications of pediatric neuromuscular disorders. Phys Med Rehabil Clin N Am 26:21-28, 2015

35. Sleigh G, Brocklehurst P: Gastrostomy feeding in cerebral palsy: a systematic review. Arch Dis Child 89:534-539, 2004

36. Sleigh G, Sullivan PB, Thomas AG: Gastrostomy feeding versus oral feeding alone for children with cerebral palsy. Cochrane Database Syst Rev (2):CD003943, 2004

37. Watanabe K, Uno K, Suzuki T, Kawakami N, Tsuji T, Yanagida $\mathrm{H}$, et al: Risk factors for complications associated with growing-rod surgery for early-onset scoliosis. Spine (Phila Pa 1976) 38:E464-E468, 2013

38. Watanabe K, Uno K, Suzuki T, Kawakami N, Tsuji T, Yanagida $\mathrm{H}$, et al: Risk factors for proximal junctional kyphosis associated with dual-rod growing-rod surgery for early-onset scoliosis. Clin Spine Surg 29:E428-E433, 2016
39. Wazeka AN, DiMaio MF, Boachie-Adjei O: Outcome of pediatric patients with severe restrictive lung disease following reconstructive spine surgery. Spine (Phila Pa 1976) 29:528-535, 2004

40. Ye J, Liu H, Zhang G, Huang Z, Huang P, Li Y: Postoperative respiratory complications of adenotonsillectomy for obstructive sleep apnea syndrome in older children: prevalence, risk factors, and impact on clinical outcome. J Otolaryngol Head Neck Surg 38:49-58, 2009

\section{Disclaimer}

The opinions or assertions contained herein are the private views of the authors and are not to be construed as official or reflecting the views of the Department of Defense or US Government. The authors are employees of the US government. This work was prepared as part of their official duties and, as such there is no copyright to be transferred.

\section{Disclosures}

Dr. Fletcher: consultant for Medtronic Spine, Zimmer Biomet, and Orthopaediatrics. Dr. Murphy: consultant for DePuy Synthes Spine. Dr. Devito: consultant for Medicrea Spine, Sea Spine, and Spinecraft; royalties from Medicrea; research support from K2M, Mazor Surgical Technologies, and Medicrea; and paid speaker for $\mathrm{K} 2 \mathrm{M}$.

\section{Author Contributions}

Conception and design: Shaw, Murphy. Acquisition of data: Shaw. Analysis and interpretation of data: all authors. Drafting the article: all authors. Critically revising the article: Fletcher, Devito, Murphy. Reviewed submitted version of manuscript: all authors. Approved the final version of the manuscript on behalf of all authors: Shaw. Statistical analysis: Shaw. Study supervision: Fletcher, Devito, Murphy.

\section{Supplemental Information \\ Previous Presentations}

Results from this study were presented at the 59th Annual Society of Military Orthopaedic Surgeons Meeting, Scottsdale, Arizona, December 14, 2017.

\section{Correspondence}

K. Aaron Shaw: Dwight D. Eisenhower Army Medical Center, Fort Gordon, GA. kenneth.a.shaw34.mil@mail.mil. 